\title{
ALLOZYMES AND AREA EFFECTS IN CEPAEA NEMORALIS ON THE WESTERN BERKSHIRE DOWNS
}

\author{
MICHAEL. S. JOHNSON* \\ Department of Genetics, University of Nottingham
}

Received 15.ix.75

\section{SUMMARY}

1. Geographic variation of six loci encoding enzymes (Est-F, Lap-2, Mdh-1, Gpgd, Pgi, and $\left.T_{0-2}\right)$ and of four loci encoding shell characters $(C, B, S$, and $U)$ in Cepaea nemoralis was examined in the western Berkshire Downs, where there is an extensive area effect for the midband gene, $U^{3}$.

2. Significant pairwise associations of geographic variation were found for all combinations of the $U, S, E s t-F$, and 6pgd loci. At each of these loci, an allele which is rare outside the midband area reaches moderate to high frequencies within that area. Significant associations of $C$ with $U$, $S$, and $E s t-F$, and of $S$ with $M d h-1$ also were found. All pairwise associations reflect the area effect.

3. Multilocus geographic associations were examined by Varimax factor analysis. The midband area effect is well represented by the second Varimax axis, accounting for 20 per cent of the allelic frequency variation over all 10 loci. Variation at the $C, U, S, E s t-F$, and $6 p g d$ loci is correlated with this axis. The first Varimax axis represents structure within the midband area, accounting for 22 per cent of the allelic frequency variation, and with which several loci are correlated.

4. That several loci are associated with the midband area effect indicates that the area effect reflects substantial genetic differentiation. Whatever the cause of the area effect is, it has acted pervasively.

\section{Introduction}

In some regions, populations of the land snail Cepaea nemoralis are characterised by concentrations of particular shell morphs over large areas, irrespective of habitat background, and often with sharp transitions between adjacent areas with dissimilar morph frequencies. This phenomenon, known as " area effects", was first described in C. nemoralis from the Marlborough Downs in south-central England (Cain and Currey, 1963a). Subsequently, area effects have been described from several localities, most strikingly from upland chalk (Cain and Currey, 1963b; Carter, 1968; Arnold, 1971). Similar patterns of geographic variation have been found in the polynesian land snail Partula (Clarke, 1968; Clarke and Murray, 1971).

In order to characterise more completely the genetic basis of area effects, I have extended Carter's (1968) study of C. nemoralis from the Berkshire Downs by an investigation of enzyme polymorphisms.

\section{MAterials AND MEthods}

(i) Samples

Between September 1973, and August 1974, samples of C. nemoralis were collected from the western Berkshire Downs, England, at 47 sites (fig. 1),

* Present address: Department of Ecology and Evolution, State University of New York, Stony Brook, New York 11794, U.S.A. 


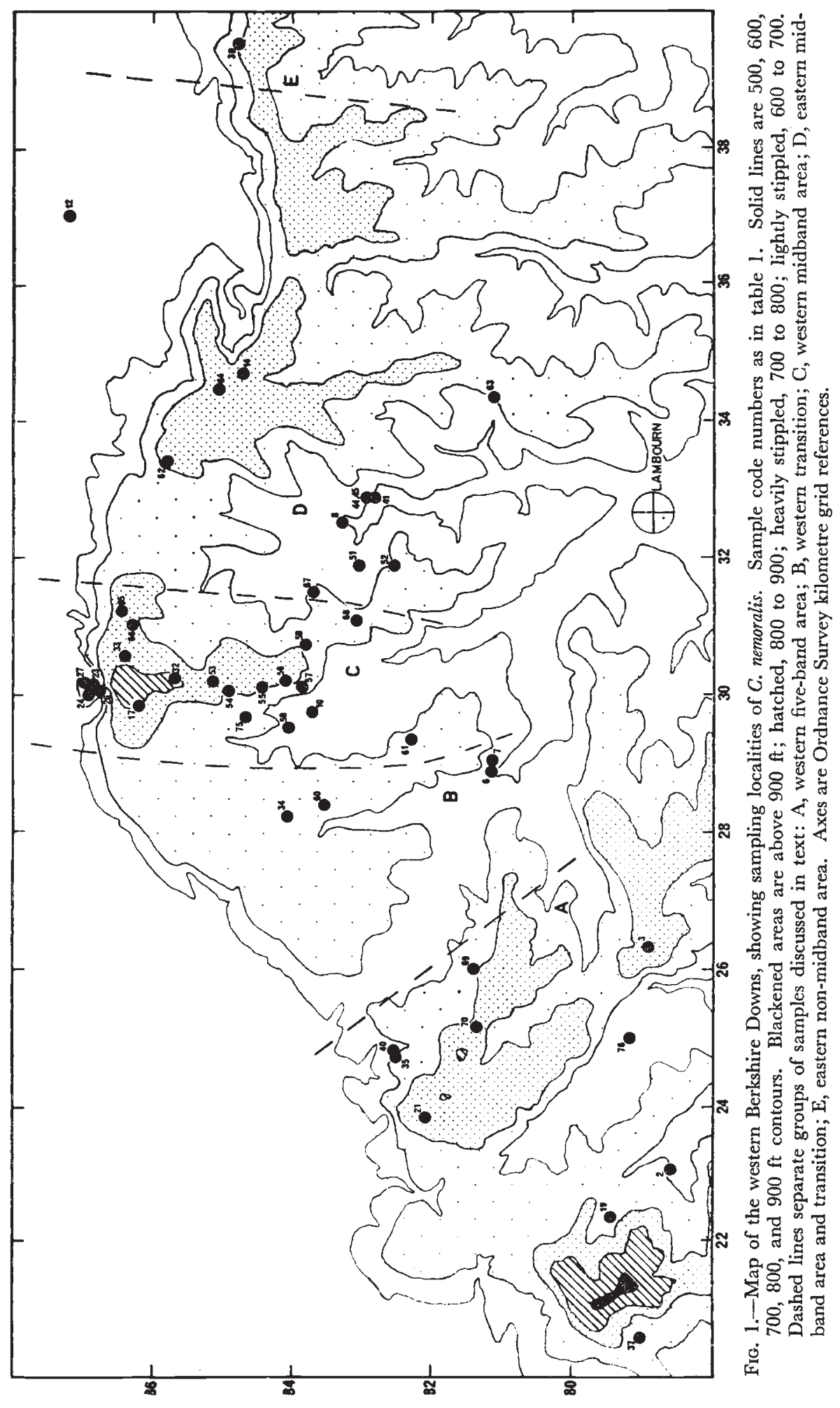


chosen to include the midband and five-band area effects defined by Carter (1968). Ordnance Survey Grid references and altitudes for each site are listed in table 1. Specimens from each locality were taken from as small an area as possible, always less than 30 metres in diameter. Adult individuals were marked with an identifying number and examined for allozymes and for shell banding and colour characters.

\section{(ii) Electrophoresis}

The snails were frozen for up to 5 months. Immediately prior to electrophoresis, dart sacs, hepatopancreas, and samples of foot were macerated separately in cold distilled water, equal volume by weight. Extracts were soaked on to filter paper inserts through a layer of filter paper.

Allozymes were separated by horizontal electrophoresis in gels of 12 per cent Electrostarch. Esterases from foot extracts, leucine aminopeptidase, malate dehydrogenase, 6-phosphogluconate dehydrogenase, phosphoglucose isomerase, and tetrazolium oxidase were assayed, using staining recipes essentially as described by Brewer (1970). With the exception of the esterases, these enzymes were not tissue specific. Although several buffer systems were used initially, the polymorphisms included in this study were routinely scored on the Tris-EDTA-Borate system described by Markert and Faulhaber (1965), with a running time of $3 \frac{1}{2}$ hours at 300 volts.

\section{(iii) Scoring of the characters}

The phenotypes and inheritance of the shell morphs of $C$. nemoralis are summarised by Cain et al. (1968). Data on four loci are presented here: colour ( $C^{Y}$, yellow; $C^{P}$, pink; $C^{B}$, brown; in order of increasing dominance); bandedness $\left(B^{B}\right.$, bands present, recessive to $B^{0}$, bands absent); spread bands ( $S S$, spread bands, dominant to $S^{0}$, normal bands); and midband ( $U^{3}$, single central band only, dominant to $U^{0}$, more than one band). Since there is dominance at each locus, allelic frequencies were estimated on the assumption of Hardy-Weinberg equilibrium.

Cepaea esterases are numerous and complex (Oxford, 1973), and only one system was scored in the present study. Esterase-F (Est-F locus) is the most anodal of the esterases found in extracts of the foot; it is not detectable in extracts of other tissues examined. This esterase produces a pink band when provided with a combination of alpha-napthyl acetate and betanapthyl acetate as substrates, indicating preferential activity on the betaisomer. Heterozygotes at the Est-F locus show two zones of activity.

The leucine aminopeptidase (Lap-2 locus) polymorphism has been described previously, consisting of three alleles and double-banded heterozygotes (Brussard and McCracken, 1974). On the Berkshire Downs, a previously unreported null allele $\left(\right.$ Lap $\left.-2^{\circ}\right)$ occurs; it is scorable in homozygotes only, these lacking activity for leucine aminopeptidase 2, but not for the monomorphic leucine aminopeptidase 1 .

The anodal malate dehydrogenase ( $M d h$ - 1 locus) and 6-phosphogluconate dehydrogenase (6pgd locus) polymorphisms have been described previously, with heterozygotes displaying three zones of activity (Manwell and Baker, 1968; Levan and Fredga, 1972). Three alleles at each locus were detected from the Berkshire Downs. Correspondence of these alleles with those previously described was not determined. 
TABle 1

Locality information and allelic frequencies at the loci affecting colour and banding for samples of $\mathrm{C}$. nemoralis from the western Berkshire Downs. Sample numbers as in fig. 1

\begin{tabular}{|c|c|c|c|c|c|c|c|c|c|c|}
\hline \multirow[b]{2}{*}{ Sample } & \multirow[b]{2}{*}{$\begin{array}{l}\text { Ordnance } \\
\text { grid }\end{array}$} & \multirow[b]{2}{*}{$\begin{array}{l}\text { Alt. } \\
\text { (ft.) }\end{array}$} & & \multicolumn{6}{|c|}{ Allele $†$} & \multirow[b]{2}{*}{$\begin{array}{l}\text { Correlation } \\
\text { of } C^{Y} \text { and } S^{\mathrm{S}}\end{array}$} \\
\hline & & & $\mathbf{N}$ & $C^{Y}$ & $C^{\mathbf{P}}$ & $C^{B}$ & $B^{B}$ & $S^{\mathbf{S}}$ & $U^{3}$ & \\
\hline \multicolumn{11}{|c|}{ A. Five-band area } \\
\hline 37. & 205791 & 650 & 45 & $0 \cdot 70$ & $0 \cdot 30$ & - & $1 \cdot 00$ & - & - & - \\
\hline 19. & 225793 & 670 & 69 & $0 \cdot 83$ & $0 \cdot 17$ & - & $1 \cdot 00$ & $0 \cdot 02$ & 一 & $-0 \cdot 07$ \\
\hline 2. & 230786 & 600 & 20 & $0 \cdot 71$ & $0 \cdot 29$ & 一 & $0 \cdot 79$ & - & - & - \\
\hline 21. & 238821 & 830 & 38 & 0.59 & $0 \cdot 41$ & - & $0 \cdot 79$ & - & 0.42 & - \\
\hline 35. & 247825 & 600 & 64 & $0 \cdot 65$ & $0 \cdot 24$ & $0 \cdot 11$ & $0 \cdot 75$ & $0 \cdot 01$ & $0 \cdot 02$ & $-0 \cdot 20$ \\
\hline 40. & 248826 & 610 & 18 & $0 \cdot 66$ & $0 \cdot 34$ & - & $0 \cdot 85$ & - & - & - \\
\hline 76. & 250792 & 630 & 25 & 0.53 & 0.43 & $0 \cdot 04$ & 0.53 & - & 一 & - \\
\hline 70. & 251814 & 720 & 57 & $0 \cdot 35$ & $0 \cdot 64$ & $0 \cdot 01$ & $0 \cdot 98$ & 0.03 & - & -0.09 \\
\hline 69. & 260814 & 670 & 40 & $0 \cdot 81$ & $0 \cdot 19$ & - & $1 \cdot 00$ & 0.08 & - & $0 \cdot 16$ \\
\hline 3. & 263789 & 750 & 37 & $0 \cdot 82$ & $0 \cdot 11$ & $0 \cdot 07$ & 0.94 & $0 \cdot 02$ & 0.06 & $0 \cdot 09$ \\
\hline \multicolumn{11}{|c|}{ B. Western transition area } \\
\hline 34. & 282841 & 650 & 46 & $0 \cdot 83$ & $0 \cdot 13$ & $0 \cdot 04$ & 0.99 & $0 \cdot 03$ & $0 \cdot 07$ & $0 \cdot 15$ \\
\hline 60. & 284836 & 740 & 60 & $0 \cdot 71$ & $0 \cdot 17$ & $0 \cdot 12$ & $1 \cdot 00$ & $0 \cdot 09$ & 0.34 & $0 \cdot 09$ \\
\hline 6. & 288812 & 500 & 19 & $0 \cdot 56$ & 0.41 & $0 \cdot 03$ & 0.82 & - & $0 \cdot 18$ & - \\
\hline 7. & 290812 & 530 & 65 & $0 \cdot 70$ & $0 \cdot 30$ & - & 0.82 & 0.05 & $0 \cdot 10$ & $-0 \cdot 16$ \\
\hline
\end{tabular}

C. Western midband area

\begin{tabular}{|c|c|c|c|c|c|c|c|c|c|c|}
\hline \multirow{2}{*}{\multicolumn{11}{|c|}{293823}} \\
\hline & & 660 & 37 & 0.90 & 0.09 & - & 0.97 & 0.37 & 0.71 & $0 \cdot 18$ \\
\hline 58. & 295841 & 580 & 55 & 0.76 & 0.24 & - & 1.00 & $0 \cdot 16$ & $0 \cdot 18$ & $0 \cdot 36^{*}$ \\
\hline 75. & 297847 & 650 & 44 & 0.99 & 0.01 & - & $1 \cdot 00$ & 0.26 & 0.57 & $0 \cdot 14$ \\
\hline 10. & 298837 & 550 & 49 & 0.58 & 0.42 & - & 0.99 & $0 \cdot 12$ & 0.69 & 0.04 \\
\hline 17. & 298862 & 810 & 51 & 0.79 & 0.21 & - & $1 \cdot 00$ & 0.25 & 0.52 & $0 \cdot 44 * *$ \\
\hline 24. & 300869 & 600 & 34 & 0.66 & 0.23 & $0 \cdot 11$ & 0.98 & 0.31 & 0.42 & 0.38 \\
\hline 57. & 301839 & 650 & 47 & 0.98 & 0.02 & - & 0.99 & $0 \cdot 32$ & 0.70 & $0 \cdot 23$ \\
\hline 55. & 301845 & 710 & 21 & $1 \cdot 00$ & - & 一 & 0.98 & 0.39 & $1 \cdot 00$ & - \\
\hline 54. & 301849 & 700 & 42 & 0.99 & 0.01 & - & $1 \cdot 00$ & 0.33 & $0 \cdot 62$ & $0 \cdot 17$ \\
\hline 26. & 301868 & 650 & 48 & 0.59 & 0.39 & $0 \cdot 02$ & $1 \cdot 00$ & 0.40 & 0.40 & $0 \cdot 47^{*}$ \\
\hline 56. & 302842 & 700 & 60 & 0.91 & 009 & - & 0.99 & 0.25 & 0.87 & $0 \cdot 15$ \\
\hline 53. & 302852 & 760 & 31 & $1 \cdot 00$ & - & - & $1 \cdot 00$ & 0.35 & 0.75 & - \\
\hline 32. & 302857 & 800 & 75 & 0.99 & 0.01 & 一 & 0.99 & $0 \cdot 22$ & 0.25 & 0.25 \\
\hline 23. & 302869 & 600 & 25 & 0.57 & 0.43 & - & $1 \cdot 00$ & 0.42 & 0.43 & $0 \cdot 20$ \\
\hline 27. & 302870 & 550 & 41 & 0.56 & 0.33 & $0 \cdot 11$ & $1 \cdot 00$ & $0 \cdot 28$ & 0.46 & 0.30 \\
\hline 33. & 306864 & 770 & 21 & 0.95 & 0.05 & - & 0.98 & $0 \cdot 22$ & 0.61 & 0.27 \\
\hline 59. & 307838 & 680 & 53 & 0.99 & 0.01 & - & $0 \cdot 86$ & 0.32 & 0.58 & $0 \cdot 18$ \\
\hline 66. & 310863 & 700 & 21 & 0.84 & $0 \cdot 16$ & - & 0.95 & 0.39 & 0.44 & -0.05 \\
\hline 68. & 311831 & 660 & 42 & $1 \cdot 00$ & - & - & 0.72 & $0 \cdot 12$ & 0.63 & - \\
\hline 65. & 312865 & 710 & 46 & 0.97 & 0.03 & - & 1.00 & 0.34 & $0 \cdot 38$ & -0.23 \\
\hline$E a$ & nidband a & d trar & & & & & & & & \\
\hline 67. & 315837 & 600 & 36 & 0.94 & 0.06 & - & 0.55 & $0 \cdot 15$ & 0.48 & 0.29 \\
\hline 52. & 319826 & 600 & 40 & 0.94 & 0.06 & - & 0.96 & $0 \cdot 18$ & $0 \cdot 21$ & $0 \cdot 15$ \\
\hline 51. & 319831 & 540 & 55 & 0.97 & 0.03 & - & 0.89 & 0.02 & 0.74 & 0.06 \\
\hline 8. & 325833 & 500 & 22 & $0 \cdot 85$ & $0 \cdot 15$ & - & 0.80 & - & $0 \cdot 62$ & - \\
\hline 41. & 328828 & 500 & 38 & 0.78 & 0.22 & - & 0.92 & 0.13 & 0.53 & -0.16 \\
\hline 44. & 329829 & 500 & 31 & 0.88 & 0.12 & - & 0.93 & $0 \cdot 36$ & 0.57 & 0.20 \\
\hline 45. & 329829 & 500 & 70 & 0.79 & $0 \cdot 14$ & 0.07 & 0.91 & 0.25 & $0 \cdot 54$ & 0.03 \\
\hline 62. & 335858 & 750 & 49 & $1 \cdot 00$ & - & - & 0.99 & 0.05 & $0 \cdot 48$ & - \\
\hline 63. & 344813 & 650 & 40 & 0.96 & 0.04 & - & 0.96 & $0 \cdot 18$ & 0.77 & $0 \cdot 17$ \\
\hline 64. & 344851 & 750 & 29 & 0.95 & 0.05 & - & $0 \cdot 70$ & $0 \cdot 16$ & $0 \cdot 62$ & $-0 \cdot 11$ \\
\hline 14. & 347847 & 730 & 54 & $1 \cdot 00$ & - & - & $1 \cdot 00$ & 0.36 & $0 \cdot 88$ & - \\
\hline 12. & 371873 & 350 & 45 & 0.95 & 0.04 & 0.01 & 0.98 & 0.02 & $0 \cdot 42$ & 0.06 \\
\hline
\end{tabular}

E. Eastern non-midband area
39 .
395848
$700 \quad 29$

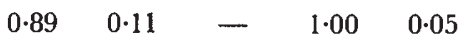
$0 \cdot 17$

$\dagger$ Frequencies of $B^{o}, S^{o}$, and $U^{o}$ are one minus the frequencies of their respective alternative alleles.

** $\mathrm{P}<0.051\}$ From Yates Chi-square. 
The phosphoglucose isomerase (Pgi locus) and tetrazolium oxidase (To-2 locus) polymorphisms have not been described before. Each polymorphism consists of two alleles, with heterozygotes displaying three zones of activity.

At each of the six enzyme loci, alleles are labelled alphabetically, beginning with the allele encoding the most anodal allozyme. The genetic basis of the polymorphism has been demonstrated for Lap-2 only (Brussard and McCracken, 1974), not including the null allele at that locus. Preliminary results indicate Mendelian segregation at the other loci as well, but the data will be presented elsewhere when complete. The phenotypes at each locus are similar to those of known genetic polymorphisms of the same enzymes in other organisms.

With the exception of Lap-2, allelic frequencies at the enzyme loci were calculated directly from observed genotypic frequencies. In those populations segregating for the null allele, Lap-2 allelic frequencies were calculated on the assumption of Hardy-Weinberg equilibrium.

\section{(iv) Geographic associations of characters}

A medial test (Quenouille, 1972) was used to find pairwise geographic associations among the loci. To clarify and quantify patterns of geographic variation over all loci, a Varimax factor analysis (Gould, 1967) of all allelic frequencies (i.e. an R-mode analysis) was conducted, using the BioMedUCLA programme at the University of Virginia Computing Center. The Varimax solution determines the principal axes of covariation among the characters, such that each character tends to load very heavily or very weakly on a given axis. Allelic frequencies were angularly transformed (Sokal and Rohlf, 1969) prior to factor analysis.

Contrary to usual procedure, the characters were not standardised. Standardisation assigns equal weight to each character, irrespective of the actual variances of the characters. Since sets of allelic frequencies are sets of equivalently scaled characters, however, it is more appropriate to weight each allele by its absolute variance in frequency.

Populations were assigned scores on each Varimax axis in the following way:

$$
\text { Score }=\Sigma \sqrt{\left(\arcsin p_{i}\right)} \times r_{i},
$$

where $p_{i}$ is the frequency of the $i$ th allele, and $r_{i}$ is the correlation of the $i$ th allele with the axis in question.

\section{Results}

\section{(i) Variation of allelic frequencies}

The present samples (table 1) reflect the pattern of shell morph distribution described by Carter (1968). The variation is greatest for the midband gene, which has a bimodal distribution of allelic frequencies. Samples from the Lambourn Downs (groups $\mathrm{C}$ and D of table 1) have high frequencies of $U^{3}$ whereas the western samples (group A) have low frequencies of this allele (fig. 2). Spread-banded shells also are common on the Lambourn Downs and rare to the west (fig. 3). Finally, most samples from the Lambourn area have high frequencies of yellow shells. 


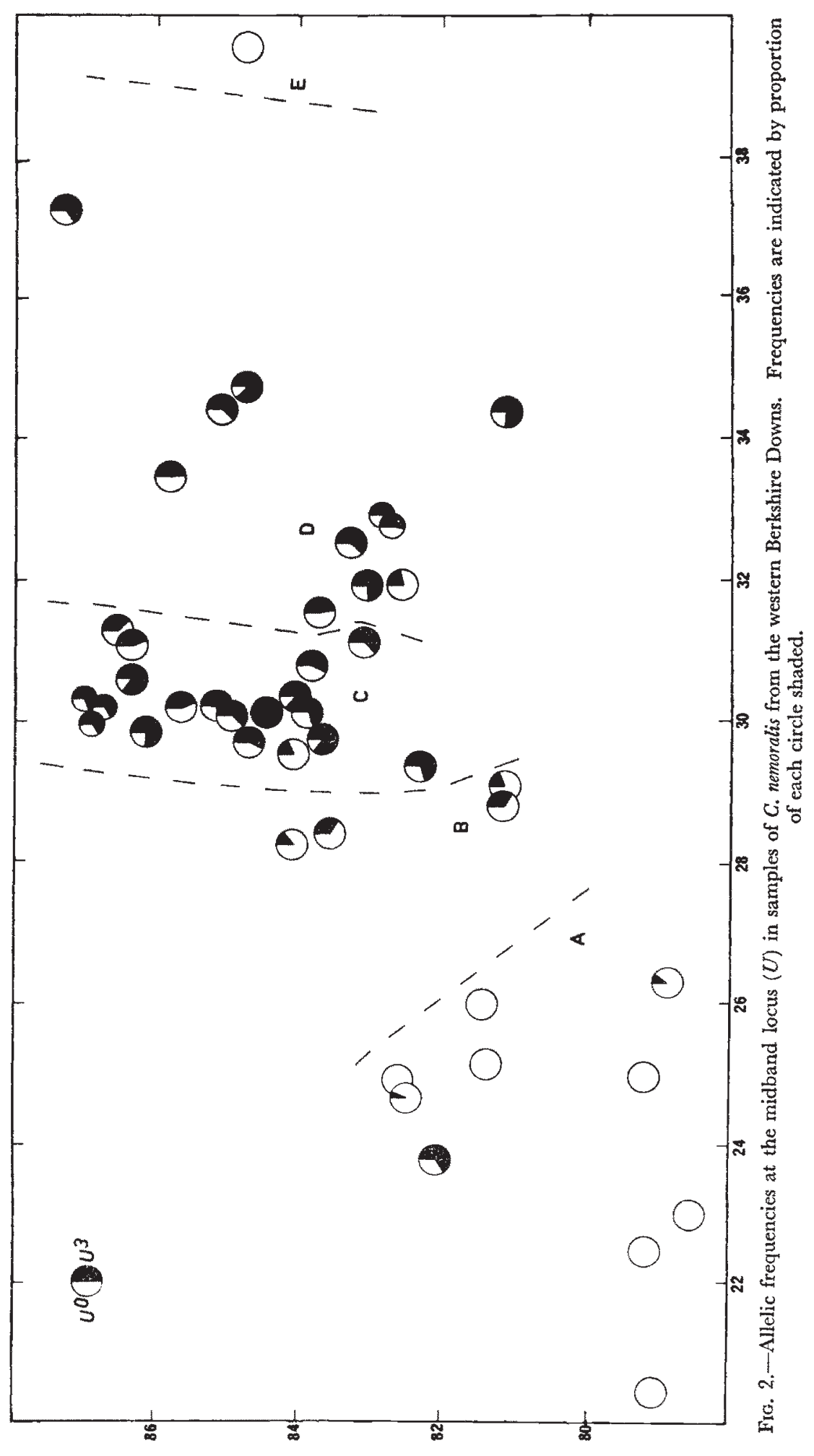




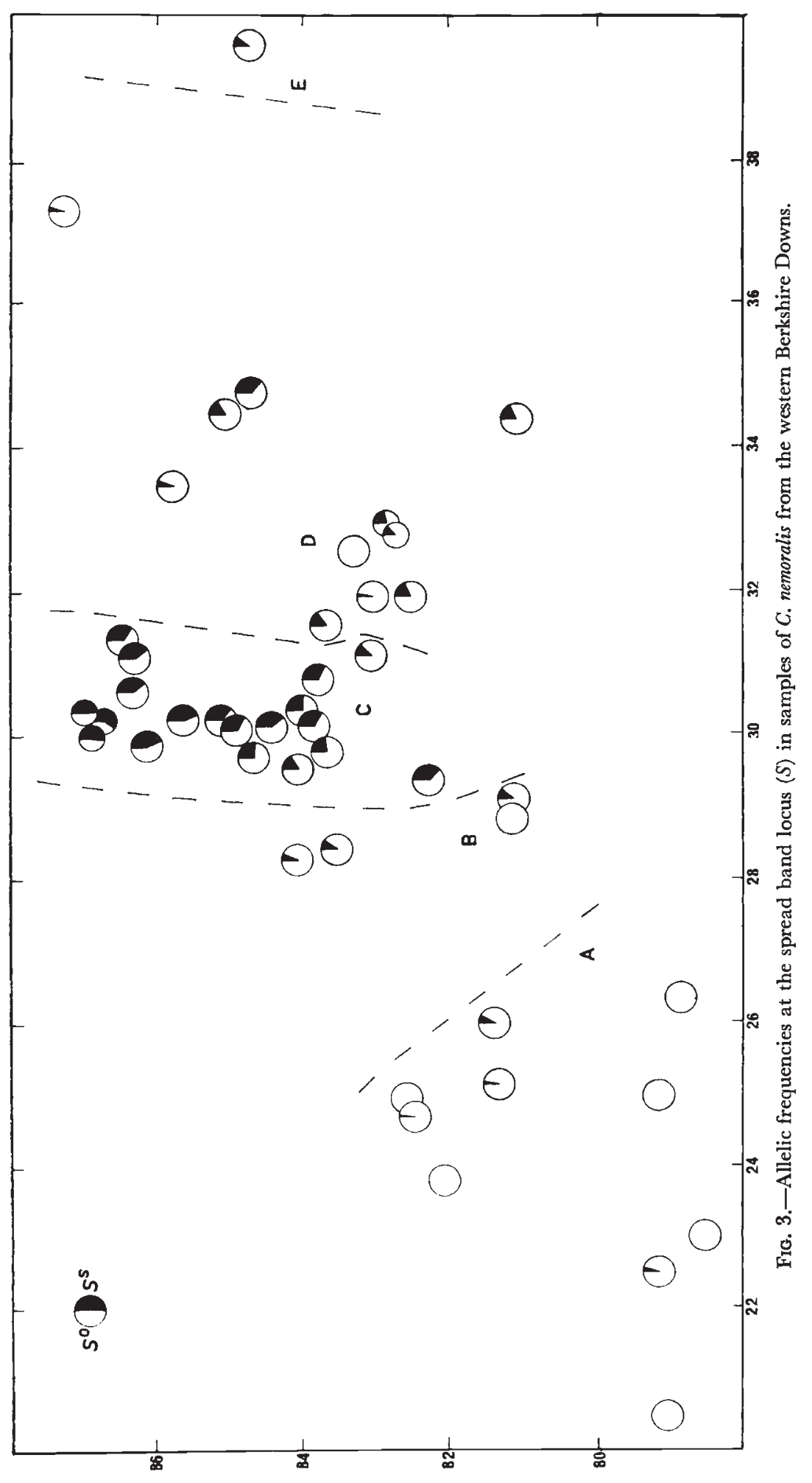


TABle 2

Allelic frequencies at six loci encoding allozymes in samples of $\mathrm{C}$. nemoralis. Sample numbers and sample sizes as in table 1

\begin{tabular}{|c|c|c|c|c|c|c|c|c|c|c|c|c|c|}
\hline \multirow[b]{2}{*}{ Sample } & \multirow{2}{*}{$\begin{array}{c}* E s t-F \\
a\end{array}$} & \multicolumn{4}{|c|}{$L a p-2$} & \multicolumn{3}{|c|}{$M d h-1$} & \multicolumn{3}{|c|}{$6 p g d$} & \multirow{2}{*}{${ }_{b}^{*} P_{b i}$} & \multirow{2}{*}{$\begin{array}{c}* T_{0}-2 \\
b\end{array}$} \\
\hline & & $a$ & $b$ & $c$ & 0 & $a$ & $b$ & $c$ & $a$ & $b$ & $c$ & & \\
\hline \multicolumn{14}{|c|}{ A. Five-band area } \\
\hline 37. & $0 \cdot 11$ & $0 \cdot 21$ & 0.60 & - & $0 \cdot 19$ & 0.96 & 0.04 & - & - & $1 \cdot 00$ & - & 0.99 & 0.90 \\
\hline 19. & 0.04 & 0.43 & $0 \cdot 25$ & - & 0.32 & $0 \cdot 66$ & 0.34 & - & - & $1 \cdot 00$ & - & 0.99 & 0.99 \\
\hline 2. & $0 \cdot 02$ & $0 \cdot 28$ & $0 \cdot 28$ & - & $0 \cdot 45$ & $0 \cdot 64$ & 0.33 & 0.03 & $0 \cdot 02$ & 0.98 & - & $1 \cdot 00$ & $0 \cdot 86$ \\
\hline 21. & - & $0 \cdot 28$ & 0.60 & - & $0 \cdot 12$ & $0 \cdot 17$ & $0 \cdot 28$ & $0 \cdot 56$ & - & $1 \cdot 00$ & - & 0.86 & 0.67 \\
\hline 35. & - & 0.72 & $0 \cdot 28$ & - & - & 0.39 & $0 \cdot 34$ & 0.27 & - & $1 \cdot 00$ & - & 0.83 & 0.56 \\
\hline 40. & - & $0 \cdot 61$ & $0 \cdot 39$ & - & - & 0.50 & 0.50 & - & - & $1 \cdot 00$ & - & 0.86 & 0.67 \\
\hline 76. & - & $0 \cdot 25$ & 0.55 & - & $0 \cdot 20$ & 0.48 & 0.44 & 0.08 & - & 0.98 & 0.02 & 0.74 & 0.72 \\
\hline 70. & - & 0.50 & 0.36 & 0.01 & $0 \cdot 13$ & $0 \cdot 19$ & 0.03 & 0.78 & - & $1 \cdot 00$ & - & 0.99 & 0.78 \\
\hline 69. & - & 0.47 & $0 \cdot 28$ & 0.03 & 0.22 & 0.44 & $0 \cdot 28$ & $0 \cdot 29$ & - & $1 \cdot 00$ & - & $1 \cdot 00$ & 0.76 \\
\hline 3. & 0.04 & $0 \cdot 13$ & 0.71 & - & $0 \cdot 16$ & 0.55 & 0.45 & - & - & 1.00 & - & 1.00 & 0.90 \\
\hline
\end{tabular}

B. Western transition area

$\begin{array}{rccccccccccccc}34 . & 0.03 & 0.20 & 0.80 & - & - & 0.63 & 0.23 & 0.14 & - & 0.95 & 0.05 & 0.99 & 0.92 \\ 60 . & 0.03 & 0.37 & 0.60 & 0.03 & - & 0.72 & 0.28 & - & 0.03 & 0.97 & - & 0.97 & 0.82 \\ 6 . & - & 0.38 & 0.62 & - & - & 0.65 & 0.15 & 0.20 & - & 0.76 & 0.24 & 1.00 & 0.87 \\ 7 . & 0.04 & 0.20 & 0.44 & 0.04 & 0.31 & 0.58 & 0.11 & 0.32 & 0.01 & 0.88 & 0.11 & 0.91 & 0.84\end{array}$

C. Western midband area

\begin{tabular}{|c|c|c|c|c|c|c|c|c|c|c|c|c|c|}
\hline 61. & 0.24 & $0 \cdot 20$ & $0 \cdot 80$ & - & - & 0.55 & $0 \cdot 15$ & 0.30 & 0.01 & 0.59 & 0.39 & 0.97 & 0.74 \\
\hline 58. & 0.24 & 0.07 & 0.66 & - & 0.27 & 0.65 & - & 0.35 & - & 0.70 & 0.30 & 0.99 & $1 \cdot 00$ \\
\hline 75. & 0.03 & $0 \cdot 16$ & 0.84 & - & - & 0.40 & - & 0.60 & - & 0.68 & 0.32 & 1.00 & 0.99 \\
\hline 10. & 0.42 & $0 \cdot 15$ & $0 \cdot 85$ & - & - & 0.44 & 0.36 & $0 \cdot 20$ & - & 0.44 & 0.56 & 1.00 & 0.66 \\
\hline 17. & $0 \cdot 15$ & 0.08 & 0.77 & 0.01 & $0 \cdot 14$ & 0.92 & - & 0.08 & - & 0.83 & $0 \cdot 17$ & 1.00 & 0.93 \\
\hline 24. & 0.06 & 0.04 & 0.63 & $0 \cdot 16$ & 0.17 & 0.83 & 0.02 & $0 \cdot 15$ & - & 0.84 & $0 \cdot 16$ & 1.00 & 0.74 \\
\hline 57. & $0 \cdot 24$ & 0.03 & 0.97 & - & - & 0.85 & - & $0 \cdot 15$ & - & 0.67 & 0.33 & 1.00 & 0.91 \\
\hline 55. & 0.40 & 0.45 & 0.55 & - & - & 0.81 & - & $0 \cdot 19$ & - & 0.71 & 0.29 & 1.00 & 1.00 \\
\hline 54. & $0 \cdot 16$ & $0 \cdot 28$ & 0.31 & - & 0.41 & 0.68 & - & 0.32 & - & 0.49 & 0.51 & 1.00 & $1 \cdot 00$ \\
\hline 26. & - & 0.06 & 0.47 & $0 \cdot 18$ & 0.29 & 0.71 & 0.02 & 0.26 & - & 0.57 & 0.43 & $1 \cdot 00$ & 0.79 \\
\hline 56. & 0.42 & 0.09 & 0.91 & - & - & 0.82 & - & $0 \cdot 18$ & - & 0.56 & 0.44 & 1.00 & 0.88 \\
\hline 53. & $0 \cdot 21$ & 0.33 & 0.49 & - & $0 \cdot 18$ & 0.79 & - & 0.21 & - & 0.61 & 0.39 & $1 \cdot 00$ & 0.97 \\
\hline 32. & 0.25 & $0 \cdot 15$ & 0.85 & - & & 0.86 & 0.05 & 0.09 & - & 0.41 & 0.59 & 0.99 & 0.99 \\
\hline 23. & $0 \cdot 12$ & 0.21 & 0.42 & 0.02 & 0.35 & 0.80 & - & $0 \cdot 20$ & - & 0.84 & $0 \cdot 16$ & $1 \cdot 00$ & 0.78 \\
\hline 27. & 0.02 & - & $0 \cdot 79$ & 0.05 & 0.15 & 0.57 & 0.23 & 0.20 & - & 0.77 & 0.23 & 0.99 & 0.68 \\
\hline 33. & 0.31 & $0 \cdot 10$ & 0.66 & 0.02 & 0.22 & 0.71 & 0.02 & 0.26 & - & 0.79 & 0.21 & $1 \cdot 00$ & 1.00 \\
\hline 59. & $0 \cdot 10$ & 0.24 & 0.37 & - & $0 \cdot 24$ & 0.95 & - & 0.05 & - & 0.68 & 0.32 & 1.00 & 0.96 \\
\hline 66. & $0 \cdot 26$ & 0.20 & 0.53 & 0.06 & 0.22 & 0.69 & - & 0.31 & - & 0.98 & 0.02 & 1.00 & 0.95 \\
\hline 68. & - & - & 0.49 & 0.08 & 0.44 & 0.94 & 0.01 & 0.05 & - & 0.07 & 0.93 & 1.00 & $1 \cdot 00$ \\
\hline 65. & 0.49 & 0.08 & 0.66 & 0.01 & 0.26 & 0.68 & 0.01 & $0 \cdot 30$ & - & 1.00 & - & 1.00 & 0.88 \\
\hline
\end{tabular}

D. Eastern midband area and transition

$\begin{array}{rccccccccccccc}\text { 67. } & 0.12 & 0.18 & 0.58 & - & 0.24 & 0.10 & 0.89 & 0.01 & - & 0.92 & 0.08 & 0.97 & 0.61 \\ \text { 52. } & 0.05 & 0.26 & 0.30 & 0.02 & 0.42 & 0.22 & 0.71 & 0.06 & 0.10 & 0.69 & 0.21 & 1.00 & 0.51 \\ 51 . & - & 0.37 & 0.36 & - & 0.27 & 0.34 & 0.34 & 0.32 & - & 0.75 & 0.25 & 0.92 & 0.71 \\ \text { 8. } & - & 0.73 & 0.27 & - & - & 0.32 & 0.36 & 0.32 & - & 1.00 & - & 1.00 & 0.91 \\ \text { 41. } & - & 0.46 & 0.30 & 0.07 & 0.16 & 0.75 & 0.24 & 0.01 & - & 0.93 & 0.07 & 0.86 & 0.87 \\ 44 . & 0.06 & 0.19 & 0.29 & 0.08 & 0.44 & 0.61 & 0.32 & 0.06 & - & 1.00 & - & 0.92 & 0.83 \\ 45 . & 0.06 & 0.12 & 0.35 & 0.02 & 0.51 & 0.65 & 0.25 & 0.10 & - & 0.99 & 0.01 & 0.97 & 0.88 \\ 62 . & 0.08 & 0.44 & 0.41 & - & 0.16 & 0.12 & - & 0.88 & 0.01 & 0.79 & 0.20 & 0.67 & 0.67 \\ 63 . & 0.12 & 0.42 & 0.58 & - & - & 0.92 & - & 0.08 & - & 1.00 & - & 1.00 & 0.55 \\ 64 . & 0.09 & 0.35 & 0.33 & - & 0.32 & 0.52 & 0.16 & 0.33 & - & 1.00 & - & 0.88 & 0.88 \\ 14 . & 0.01 & 0.26 & 0.28 & - & 0.46 & 0.61 & 0.11 & 0.28 & - & 1.00 & - & 0.91 & 0.83 \\ 12 . & - & - & 0.53 & 0.32 & 0.15 & 0.58 & 0.40 & 0.02 & 0.08 & 0.92 & - & 0.86 & 0.56\end{array}$

\section{E. Eastern non-midband area}
39.
$\begin{array}{lll}0.02 & 0.10 & 0.90\end{array}$
$0.50 \quad 0.09 \quad 0.41$
$0 \cdot 86$
$1 \cdot 00$

* Frequencies for one allele only are given for those loci segregating for two alleles. 
As in the shell characters, there is considerable geographic variation in the allozymes (table 2). The clearest patterns of variation are for $E s t-F$ and $6 p g d$. The Est-Fa and $6 p g d^{c}$ alleles reach moderate to high frequencies in the area of high frequencies of $U^{3}$ and $S$, , but have negligible frequencies in the western samples (figs. 4 and 5). Such marked geographic concentrations are not evident for the other allozymes.

\section{(ii) Geographic associations of allelic frequencies}

The similarity of patterns of geographic variation at the $U, S, E s t-F$, and 6pgd loci evidenced by figs. 2 to 5 is statistically significant (table 3 ). These four loci form a group, within which all pairs show significant associations of allelic frequencies. At each of these loci, the allele correlated with the midband area effect is rare to absent outside that area. The frequency of $C^{Y}$ is also significantly associated with $U^{3}, S^{S}$, and $E s t-F^{a}$, but $C^{Y}$ also occurs at high frequencies outside the midband area. The only other significant pairwise associations are between $S$ and both $L a p-2$ and $M d h-1$.

All of the statistically significant associations reflect the area effect on the Lambourn Downs. Allelic frequencies among the loci are neither strongly nor independently correlated, however. Calculation of partial correlation coefficients among $U, S, E s t-F$, and 6pgd revealed significant independent correlations between $U^{3}$ and $S S$ and between $S S$ and $E s t-F^{a}$ only. Rather than a close correlation between pairs of loci, there is a tendency for certain alleles to be relatively common in the same general area.

To clarify and quantify this complex of interlocus combinations, Varimax axes of covariation in the frequencies of all 25 alleles were computed (table 4). Only the first two axes need be considered, as only they produced obvious geographical groupings. Both axes relate to the area effect. The midband area effect is well represented by the Varimax II axis, with which the midband locus correlates strongly. Colour and spread-band also load heavily, and $E s t-F$ and $6 p g d$ are the only other loci with correlations exceeding $0 \cdot 5$. This axis represents 20 per cent of the allelic frequency variation, averaged over the 25 alleles.

The Varimax I axis indicates a pattern of covariation within the midband area, representing an average of 22 per cent of the variation in allelic frequencies. Variation at the $S, E s t-F$, and $6 p g d$ loci is correlated with Varimax I at approximately the same level as with Varimax II. Varimax I represents an association of alleles along a ridge running south from White Horse Hill (i.e. south of sample 17) in the western half of the midband area. In this more restricted region, populations are nearly fixed for $B^{B}, P_{g i}{ }^{b}$, and $\mathrm{T}_{0}-2^{b}$, have relatively high frequencies of $M d h-1^{a}$ and $L a p-2^{b}$, and have low frequencies of $M d h-1^{b}$ and $L a p-2^{a}$ (group C, tables 1 and 2).

Combination of the two axes provides a particularly clear picture of geographic variation in the ten loci (fig. 6). Varimax II separates the midband area effect of the Lambourn Downs from the five-band area effect to the west. Varimax I separates the populations in the western portion of the midband area from all other populations, both east and west. Five geographically contiguous and non-overlapping groups of populations 


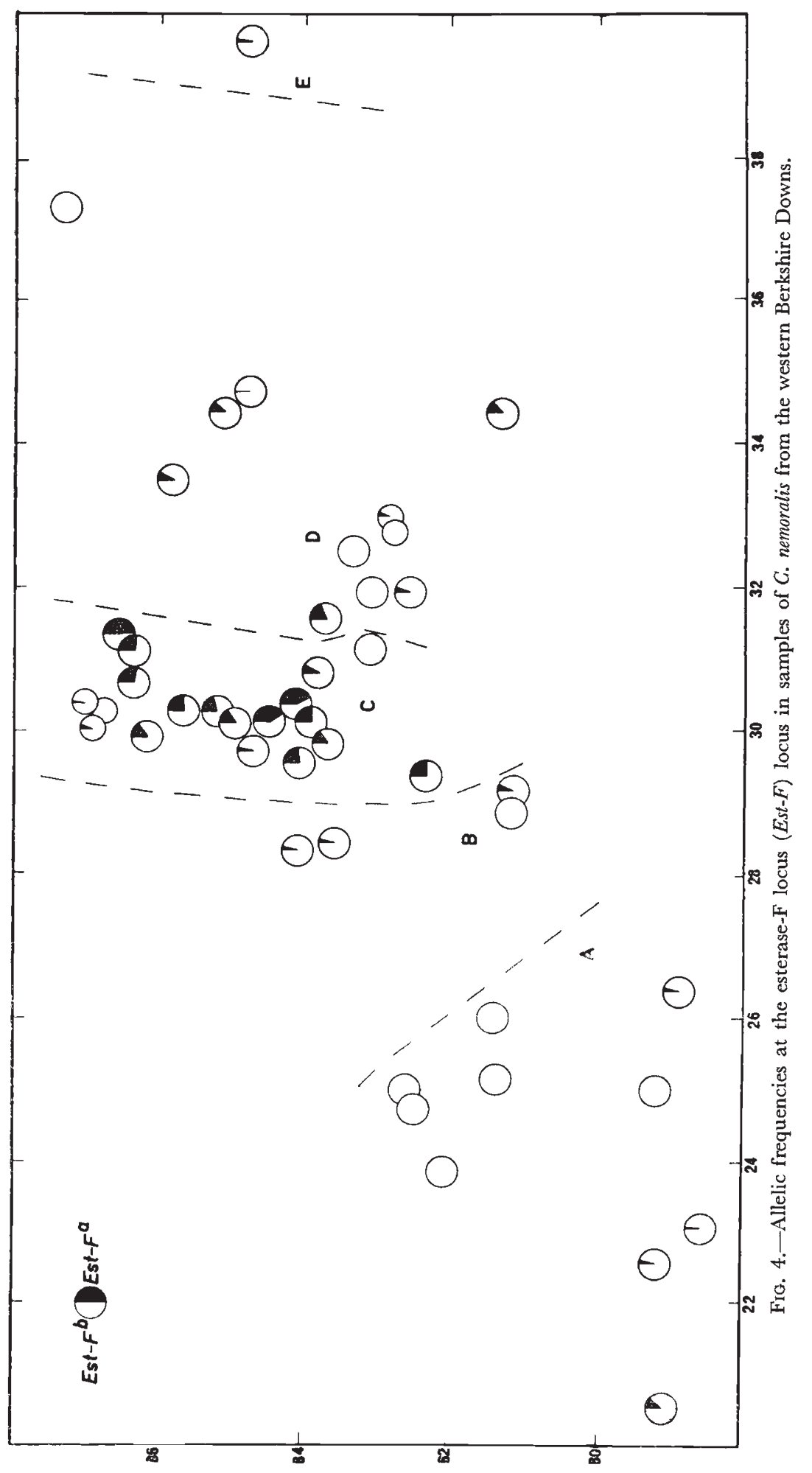




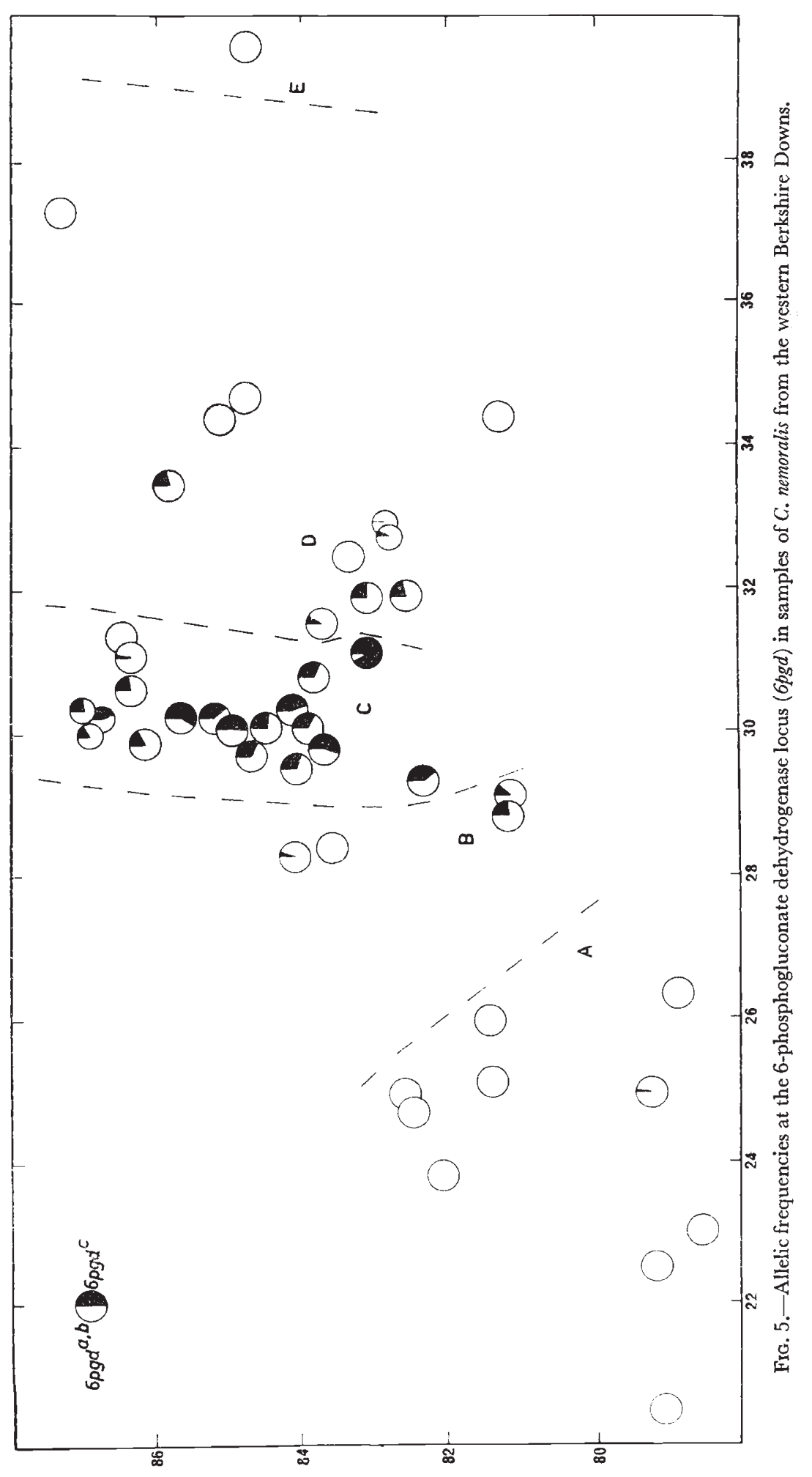


TABLE 3

\begin{tabular}{|c|c|c|c|c|c|c|c|c|c|}
\hline \multicolumn{10}{|c|}{ Pairwise geographic associations among the loci } \\
\hline & $B$ & $S$ & $U$ & Est-F & $L a p-2$ & $M d h-1$ & 6pgd & $P g i$ & $T_{0-2}$ \\
\hline$C$ & - & + & +++ & + & - & - & - & - & - \\
\hline$B$ & & - & - & - & - & - & - & - & - \\
\hline$S$ & & & + & +++ & + & +++ & ++ & - & - \\
\hline$U$ & & & & ++ & - & - & + & - & - \\
\hline Est-F & & & & & - & - & + & - & - \\
\hline Lap-2 & & & & & & - & - & - & _ \\
\hline$M d h-1$ & & & & & & & - & - & - \\
\hline 6pgd & & & & & & & & - & - \\
\hline$P g i$ & & & & & & & & & - \\
\hline
\end{tabular}

TABLE 4

Varimax factor loadings for each of the 25 alleles

\begin{tabular}{|c|c|c|c|c|c|}
\hline Allele & Axis I & Axis II & Allele & Axis I & Axis II \\
\hline$C^{Y}$ & -0.073 & 0.792 & $L a p-2^{c}$ & 0.134 & -0.044 \\
\hline$C^{P}$ & 0.025 & -0.780 & $L a p-2^{o}$ & -0.074 & 0.060 \\
\hline$C^{B}$ & 0.000 & -0.414 & $M d h-1 a$ & 0.665 & $0 \cdot 131$ \\
\hline$B^{B}$ & 0.684 & 0.039 & $M d h-1^{b}$ & -0.620 & -0.292 \\
\hline$B^{o}$ & -0.684 & -0.039 & $M d h-1^{c}$ & -0.096 & $0 \cdot 132$ \\
\hline$S s$ & 0.533 & 0.669 & $6 p g d^{a}$ & -0.254 & 0.048 \\
\hline$S^{\circ}$ & -0.533 & -0.669 & $6 p g d^{b}$ & -0.264 & -0.384 \\
\hline$U^{3}$ & 0.118 & 0.875 & $6 p g d^{c}$ & 0.410 & 0.513 \\
\hline$U^{o}$ & -0.118 & -0.875 & $P g i^{a}$ & -0.748 & -0.077 \\
\hline Est-Fa & 0.533 & 0.523 & $P g i^{b}$ & 0.748 & 0.077 \\
\hline$E s t-F^{b}$ & -0.533 & -0.523 & $T_{0-2 a}$ & -0.592 & -0.150 \\
\hline$L a p-2^{a}$ & -0.511 & -0.176 & $T_{0-2^{b}}$ & 0.592 & $0 \cdot 150$ \\
\hline$L a p-2^{b}$ & 0.505 & 0.083 & - & - & - \\
\hline
\end{tabular}

can thus be recognised on the basis of Varimax scores and geographical position:

A. The westernmost populations, representing Carter's (1968) five-band area, with low scores on both Varimax axes;

B. A relatively narrow western zone of transition;

C. The western midband area, with very high scores on both Varimax axes;

D. The eastern midband area and transition, also with high scores on Varimax II, but with lower scores on Varimax I;

E. The eastern non-midband area, represented by sample 39 .

These groups are indicated in tables 1 and 2 and in each of the figs.

The exact delineation of the groups is arbitrary, but the general trends are clear. Maximum differentiation is between the non-midband areas (groups A and E) and the western populations of the midband area (group C). Scores on both Varimax axes are highest in group C. Transition from the peculiarity of this group of populations is sharp in the west, and gradual in the east. The two Varimax axes agree in the overall structure of the area effect; population scores on the two axes are correlated within group $\mathrm{C}(r=0.62$, $\mathrm{P}<0.01)$ and within groups $\mathrm{C}$ and $\mathrm{D}$ combined $(r=0.60 . \mathrm{P}<0.01)$. 


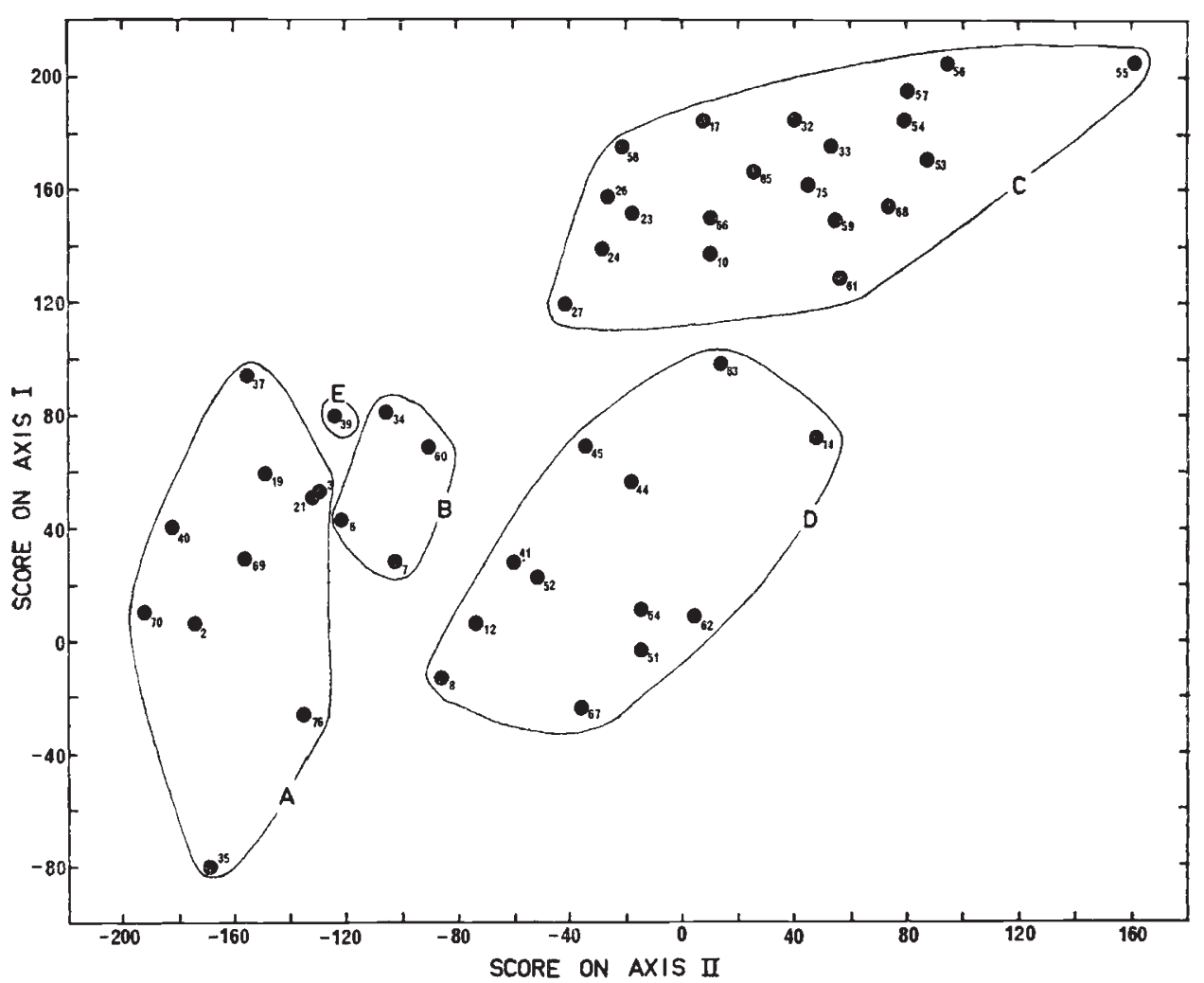

Frg. 6.-Scores on the first two Varimax axes for samples of $C$. nemoralis from the western Berkshire Downs. Sample code numbers and groupings as in fig. 1.

While geographic concentrations of several alleles focus on the same area, the extent of the concentrations varies among the loci. The extreme western portion of the midband area has peculiar frequencies at the Lap-2 $M d h-1, P g i$, and To-2 loci. The Est-Fa and $6 p g d^{c}$ alleles are more extensively associated with the midband area, and $S S$ even more so. The $U^{3}$ allele maintains high frequencies much farther eastward than do the others.

Scores on both Varimax axes are associated with altitude. Both high and low scores on Varimax II tend to be from high altitudes; intermediate scores tend to be from lower elevations. In other words, both the midband and five-band areas are uplands, while the transition samples are from lower sites. Within groups C and D, Varimax II scores are moderately correlated with altitude $(r=0 \cdot 38, \mathrm{P}<0.01)$.

On Varimax I, the five-band area is similar to the transition and eastern midband areas, so there is no overall association of this axis with altitude. High scores on this axis are associated with the highest portions of the midband area, however, Within group $\mathrm{C}$, there is a positive correlation of Varimax score with altitude $(r=0.61, \mathrm{P}<0.01)$. The lowest samples from this group, samples 27 and 10 , are approximately $3.3 \mathrm{~km}$ apart, but have similar scores on Varimax I. On the other hand, sample 27, near the bottom of White Horse Hill, is only $0.9 \mathrm{~km}$ from sample 17, near the top, and these two samples represent the extreme scores on Varimax I within group C. 


\section{(iii) Linkage disequilibrum}

In view of the geographical associations of allelic frequencies, an attempt was made to find intrapopulation associations of loci, although any such associations would have to be strong in order to be detected by the generally small sample sizes. Only $C$ and $S$ show a consistent direction of linkage disequilibrium. As reported by Carter (1968), there is an excess of yellowspread banded shells from the midband area effect (table 1). Fifteen of 17 samples segregating at both loci in group $\mathrm{C}$ show an excess of yellowspreads $(P<0 \cdot 05$, sign test). Twenty-two of 26 samples from groups $C$ and $D$ combined show this excess $(\mathrm{P}<0.05)$. Only four of eight samples from groups $\mathrm{A}$ and $\mathrm{B}$ follow this pattern, the number expected from chance alone. Although the area of linkage disequilibrium corresponds with the midband area, the intensity of disequilibrium, as measured by product-moment coefficients of correlation (table l), is not correlated with scores on either Varimax axis within the area effect.

\section{Discussion}

The clearest and most important point to emerge from the present data is that the " midband " area effect on the Lambourn Downs represents much more than a peculiarly high and extensive concentration of the $U^{3}$ allele. Geographic concentrations of $S^{S}, E s t-F^{a}$, and $6 p g d^{c}$ (figs. 3 to 5), are strikingly associated with the area effect. The association of $S S, E s t-F^{a}$, and $6 p g d^{c}$ with alleles at the Lap-2, Mdh-1,Pgi, and $T_{0}-2$ loci as represented by the Varimax I axis, further indicates extensive genetic divergence between the midband and non-midband areas.

This finding agrees with evidence from Partula that area effects represent marked genetic differentiation (Clarke, 1968). The association of visual with non-visual polymorphisms indicates that the study of shell morph frequencies is not of narrow application. In this regard, it is also interesting that there are associations of allozymes and shell morphs on a larger geographic scale in American colonies of Cepaea (Brussard, 1975).

In addition to verifying the genetic pervasiveness of the Lambourn area effect, the patterns of covariation among the 10 polymorphic loci provide a clearer description of the area effect than do frequencies of $U^{3}$ alone. This more complete picture of the area effect is relevant to, but does not resolve, the controversial question of the cause(s) of area effects.

Goodhart (1963) and Wright (1965) suggested an origin of area effects from small isolated founder populations which developed differently coadapted gene complexes. One argument against an important influence of isolation has been that the area effects for different loci are not concordant (Cain and Currey, 1963a). To judge from the larger number of loci examined here, however, there is much covariation among the loci in the western Berkshire Downs, as one would expect if the history of the area effect were one of differentiation in isolation, followed by secondary contact.

From the Marlborough Downs north and eastwards across the Berkshire Downs, there is a decrease in the intensity of area effects, paralleling a decrease in altitude and topographic variation (Carter, 1968). Within the western Berkshire Downs, this association is further evident from the correlation of Varimax scores with altitude. Carter (1968) felt that the 
correlation of area effects with regions of marked topography argued against a role of isolation. The reverse conclusion would seem as likely.

The distribution of $C$. nemoralis on the Marlborough and western Berkshire Downs is limited topographically. The low-lying areas often contain $C$. hortensis, but not $C$. nemoralis. The gap between eastern and western samples in the present study (western portion of area B, fig. 1) is such an area (Carter, 1968; personal observations). Restriction of $C$. nemoralis to higher ground could result in patterns of isolation, which would be most marked in the areas of sharp and elevated topography; i.e. in those areas with the most striking area effects. While only a suggestion, the consistency of the Lambourn area effect with possible patterns of historical isolation at least precludes the use of this area effect as evidence against a role of isolation.

If isolation played a role in the development of the Lambourn area effect, however, that role must have been long ago. Isolation across the present gap is not the cause of the area effect, because the transition to the midband area occurs east of the gap, rather than on either side of it. Also, subfossils indicate that the distribution of $C$. nemoralis has contracted, while that of C. hortensis has expanded, since the hypsithermal, about 4500 B.c. (Gurrey and Cain, 1968; Cain, 1971). Thus, the distribution of $C$. nemoralis on the Downs is probably more restricted at present than for more than 6500 years, and any role of isolation must have been during an earlier period of range contraction.

To suggest a role of isolation need not be to suggest a role of random divergence, as was done by Goodhart (1963) and Wright (1965), because isolation favours divergence through selection as well. Indeed, the patterns of variation among the loci suggests an inadequacy of random divergence. While the area of maximum differentiation of the covariant loci is in the western portion of the midband area, there are differential eastward extensions among the loci. This nested pattern of distribution would not be expected from random drift, suggesting a role of selection.

The nature of the actual selective mechanisms remains obscure, however. The covariation among several loci suggests that, if environmental selection is the main determinant of allelic frequencies, the effective parameter of the environment must act in a fundamental and pervasive manner. Climate is the most obvious such aspect of the environment. There is considerable distributional (Lamotte, 1959; Cain and Currey, 1963a, b); Arnold, 1968; Cain et al., 1968; Jones, 1973) and possibly some direct (Richardson, 1974; Bantock, 1974) evidence for climatic determination of colour morph frequencies in Cepaea. Among the allozymes, however, only Est-F is correlated with shell colour in the western Berkshire Downs, and this correlation does not hold microgeographically.

There is some evidence for climatic selection with respect to shell banding (Arnold, 1968; Currey and Cain, 1968; Cain, 1971), but a large scale trend is not evident (Jones, 1973). The most striking area effects for midbanded shells occur in highly exposed uplands, subject to environmental extremes. In the Lambourn area, this general association is further reflected by correlations of Varimax scores with altitude. In this regard, it is particularly interesting that $U^{3}$ increases on Liddington Castle (Cain and Currey, 1963a) and Charlbury Hill (sample 21, table 1), both highly exposed hilltops well outside the midband area. On Charlbury Hill, at least, there are not parallel responses at the other loci associated with the midband area effect. 
Also, the correlations of Varimax scores with altitude hold only in limited portions of the study area. Thus, until environmental parameters can be locally measured, and correlated with the microgeographic distribution of allelic frequencies, the role of climatic selection will remain an elusive possibility.

The difficulty of finding environmental correlates with area effects in Cepaea and in Partula led Clarke $(1966,1968)$ to postulate an important role of coadaptation in the origin of area effects. Evidence for coadaptation would include linkage disequilibrium and genetic disturbance in the transition zone between area effects. There is evidence for such genetic disturbance in Partula taeniata (Clarke, 1968). In the present study, there is consistent linkage disequilibrium between $C$ and $S$ within the midband area, but not outside that area. Whether larger samples would reveal disequilibrium among the other covariant loci remains to be seen. Experimental evidence that the observed linkage disequilibrium is maintained by selection is clearly desirable.

An important difficulty in the controversy on the causes of area effects is that the major hypotheses are not mutually exclusive. Indeed, one would expect much synergism between isolation, environmental selection, and coadaptation. According to one's preconception, the data here reported can be taken as evidence for several combinations of these three factors. In any case, the demonstration of pervasive genetic change associated with the Lambourn area effect makes area effects more fascinating, if not less enigmatic.

Acknowledgments. - This study was conducted during the tenure of a NATO Postdoctoral Fellowship at the University of Nottingham. I thank Professor B. C. Clarke for his hospitality. Professors Clarke, J. J. Murray, A. J. Cain, and P. M. Sheppard were kind enough to read the manuscript, and their comments were much appreciated. Mr D. T. Horsley introduced me to Cepaea in the field. The laboratory work was supported by the Nuffield Foundation, and the data analysis by funds from the University of Virginia.

\section{REFERENCES}

ARnold, R. w. 1968. Climatic selection in Cepaea nemoralis (L.) in the Pyrenees. Phil. Trans. Roy. Soc. B, 253, 549-593.

ARNOLD, R. W. 1971. Cepaea nemoralis on the east Sussex South Downs, and the nature of area effects. Heredity, 26, 277-298.

BANTOCK, C. R. 1974. Experimental evidence for non-visual selection in Cepaea nemoralis. Heredity, 33, 409-412.

Brewer, G. J. 1970. An Introduction to Isozyme Techniques. Academic Press, New York.

BRUSSARD, P. F. 1975. Geographic variation in North American colonies of Cepaea nemoralis. Evolution, in press.

BRUSSARD, P. F., AND MCGRAGKeN, G. F. 1974. Allozymic variation in a North American colony of Cepaea nemoralis. Heredity, 33, 98-101.

CAIN, A. J. 1971. Colour and banding morphs in subfossil samples of the snail Cepaea. In Ecological Genetics and Evolution, pp. 65-92 (ed. R. Creed). Blackwell, Oxford.

CAin, A. J., AND currey, J. D. 1963a. Area effects in Cepaea. Phil. Trans. Roy. Soc. B, 246, $1-83$.

CAIN, A. J., AND GURREY, J. D. 1963b. Area effects in Cepaea on the Larkhill Artillery Ranges, Salisbury Plain. Zool. J. Linn. Soc. Lond., 45, 1-15.

CAIN, A. J., SHEPPARD, P. M., AND KING, J. M. B. 1968. The genetics of some morphs and varieties of Cepaea nemoralis (L.). Phil. Trans. Roy. Soc. B, 253, 383-396.

CARTER, м. A. 1968. Area effects and visual selection in Cepaea nemoralis (L.) and Cepaea hortensis. Phil. Trans. Roy. Soc. B, 253, 397-446.

Clarke, B. 1966. The evolution of morph ratio clines. Am. Natur., 100, 389-402. 
CLARKE, B. 1968. Balanced polymorphism and regional differentiation in land snails. In Evolution and Environment, pp. 351-368 (ed. E. T. Drake). Yale University Press, New Haven.

CLARKE, B., AND MURRAY, J. 1971. Polymorphism in a polynesian land snail, Partula suturalis vexillum. In Ecological Genetics and Evolution, pp. 51-64 (ed. R. Creed). Blackwell, Oxford.

CURREY, J. D., AND CAIN, A. J. 1968. Climate and selection of banding morphs in Cepaea from the climatic optimum to the present day. Phil. Trans. Roy. Soc. B, 253, 483-498. GOODHART, c. B. 1963. "Area effects" and non-adaptive variation between populations of Cepaea (Mollusca). Heredity, 18, 459-465.

GOULD, s. J. 1967. Evolutionary patterns in pelycosaurian reptiles: a factor-analytic study. Evolution, 21, 385-401.

JONEs, J. s. 1973. Ecological genetics and natural selection in molluscs. Science, 182, 546552.

Lамотте, м. 1959. Polymorphism of natural populations of Cepaea nemoralis. Cold Spring Harb. Symp. Quant. Biol., 24, 65-84.

LEVAN, G., AND FREDGA, K. 1972. Isozyme polymorphism in three species of land snails. Hereditas, 71, 245-252.

MANWELL, C., AND BAKER, с. M. A. 1968. Genetic variation of isocitrate, malate, and 6-phosphogluconate dehydrogenases in snails of the genus Cepaea-Introgressive hybridisation, polymorphism, and pollution? Comp. Biochem. Physiol., 26, 195-209.

MARKERT, C. L., AND FAULHABER, I. 1965. Lactate dehydrogenase isozyme patterns of fish. 7. Exp. Zool., 159, 319-332.

oxpord, G. s. 1973. The genetics of Cepaea esterases. I. Cepaea nemoralis. Heredity, 30, 127-139.

QUenoullle, м. н. 1972. Rapid Statistical Calculations, 2nd edition. Hafner, New York.

RICHARDSON, A. м. м. 1974. Differential climatic selection in natural populations of land snail Cepaea nemoralis. Nature, 247, 572-573.

SOKAL, R. R., AND ROHLF, F. J. 1969. Biometry. W. H. Freeman, San Francisco.

WRIGHT, s. 1965. Factor interaction and linkage in evolution. Proc. Roy. Soc. B, 162, 80-104. 